\title{
Knowledge, Attitude and Practice of Oral Hygiene in Children of Eastern Nepal
}

\author{
Abhishek Kumr ${ }^{1}$, Varun Pratap Singh ${ }^{2}$ \\ Assistant Professor, Department of Pedodontics \& Preventive Dentistry, College of Dental Surgery, BPKIHS, \\ Dharan, Nepal \\ Associate Professor \& Head, Department of Orthodontics, College of Dental Surgery, BPKIHS, Dharan, Nepal
}

\begin{abstract}
Objectives: The objectives of the study were to study knowledge, attitude and practice of oral hygiene in the school children of eastern region of Nepal of age group 6-13 years. Methods and materials: The study was undertaken in the eastern region of Nepal with a sample population of 2,500 children in the age group of 613 years. A questionnaire which was formulated to assess knowledge, attitude and practices of oral hygiene was used. Silness and Loe Plaque index was used to record plaque scores. Results: It was found that $62.3 \%$ of the 1013 years age group had plaque score of 3 (fair) and 37.7\% had a plaque score of 4 (poor) as compared to $59.7 \%$ and $40.3 \%$ in the 6-9 years age group. The children aged 10-13 years had higher percentage of good oral hygiene compared to 6-9 years children.Conclusion: The present study concludes that in spite of good oral hygiene practices in children, their overall oral hygiene status was found to be poor. Upon investigating about the knowledge of how to maintain good oral hygiene, maximum number of children responded by brushing twice daily. This implicates that knowledge without proper practice is lacking in children of eastern Nepal.
\end{abstract}

Keywords: Knowledge, Attitude, Oral hygiene, Plaque, Eastern Nepal.

\section{Introduction}

The oral cavity is a known reservoir for pathogens to grow and thrive. Oral diseases such as gingivitis, halitosis and plaque formation are some of the consequences of poor oral hygiene Determinants of the diseases have as the complex chain of environmental and behavioral events ${ }^{1}$ such as, oral health behavior, oral hygiene level, dietary habits ${ }^{2}$, and are shaped by broader socioeconomic and socio-demographic condition. ${ }^{1}$ The most of the common dental disease can be controlled only if the individual patient exercises a considerable measure of initiative and responsibility.

Dental caries prevalence is directly proportional to habits and habitat of the population that is multi-factorial in nature, in the hands of the individuals to eradicate with a healthy dietary and oral hygiene practices. It is also influenced by the socio-economic status and affected by the cultural variation. ${ }^{3}$ Mutans streptococcus multiplies more in the fermented carbohydrate substrate ${ }^{4}$.

It is well established fact that diet and oral hygiene habits are inter-related and influenced by income, education and social environment. Hunt $(1990)^{5}$ had shown convincingly that in westernized industrialized countries people whose socio-economic status is low tend to have more carious lesion than do people with high socioeconomic status.

Children comprises of $38 \%$ of the total population of Nepal. Negligence of the oral health leads to the impairment of esthetics and functional discrepancies. The burning problem of the nation regarding health concern, priority wise infectious diseases, malnutrition and maternal and child mortality is followed by oral diseases. ${ }^{6}$

Scanty information is available concerning oral hygiene status of children on a national \& district level in the eastern development region. This prompted us to undertake present study with an aim of establishing the data for knowledge, attitude, and practice of oral health habits in children of eastern development region.

Subjects and Methods:

Eastern development region of Nepal comprises of sixteen districts of which seven districts are in the foothills of the Himalayas and comprises of $>80 \%$ of the population and nine in the hill region ${ }^{7}$. Due to presence of larger population in the Terai region, four districts from Terai and one district from hill region was selected randomly.Proportionate stratified simple random sampling technique was used to select children.

A total of 2500 children aged 6-13 years comprised of the study population. The children were selected from one government school and one private school from each of the five districts selected for the study. Before the study started, no school based oral health education existed.

The sample size was calculated using the formula $N=z^{2} \mathrm{p} * \mathrm{q} / \mathrm{l}^{2}$

Where,

$\mathrm{N}=$ sample size 
$\mathrm{Z}=$ tabulated value

$\mathrm{P}=$ prevalence of disease in Eastern Developmental Region according to previous study $(25 \%=0.25)$

Therefore $\mathrm{Q}=1-\mathrm{p}=0.75$

$\mathrm{L}^{2}=$ estimating error.

Before the commencement of the study, an informed consent from the principal of the school as well as the parents of the students participating in the study was obtained.

A questionnaire survey was conducted for children aged 6-13 years to evaluate oral hygiene practices. Oral hygiene status was recorded using plaque index.All examinations were carried out in the school courtyard or in a well-lit classroom. Recording of data was done by a trained person who assisted throughout the study. Prior to the examination for plaque, a questionnaire was filled by the subject to find out the personal data and oral hygiene habits. The children were examined by a single examiner who was trained to record the WHO oral health assessment form to avoid inter-examiner variations.

Plaque was assessed using Silness and Loe Plaque index. Plaque index was graded on a numeric scale from 0 to 3 , depending on the severity and extent of the deposits. The Plaque index values are categorized as follows:-

0

$0.1-0.9$

$1.0-1.9$

EXCELLENT 1

$2.0-3.0$

GOOD 2

FAIR 3

POOR

The six surfaces selected for assessment are as follows:-

1. Buccal of maxillary right first permanent molar (i.e. 16)

2. Labial of maxillary right lateral incisor (primary or permanent) (i.e. 52/12)

3. Buccal of maxillary left first premolar or first primary molar (i.e. 24/64)

4. Lingual of mandibular left first permanent molar (i.e. 36)

5. Lingual of mandibular left lateral incisor (primary or permanent) (i.e. $72 / 32$ )

6. Lingual of mandibular right first premolar or first primary molar (i.e. 44/84)

Missing teeth are not substituted. The surface of the tooth is given a score of 0 to 3 and scores from selected surfaces of the teeth are added and divided by the number of teeth examined to derive the plaque index for the individual.

Results

A study of knowledge, attitude and practice of oral hygiene in 2,500 children aged 6-13 years was conducted in the Eastern Developmental Region of Nepal. The data was analyzed using the statistical package SPSS version 11.5. The Pearson $\chi^{2}$ test was used for statistical analysis of data.

Table 1 illustrates the oral hygiene status indicated through plaque score of 2,500 children in the age group of 69 and 10-13 years respectively and was found that $62.3 \%$ of the 10-13 years age group had plaque score of 3 (fair) and $37.7 \%$ had a plaque score of 4 (poor) as compared to 59.7\% and $40.3 \%$ in the 6-9 years age group.

Question enquiry had been made to evaluate the knowledge regarding oral hygiene practices, knowledge of fluorides and use of mouth washes, food habits and dental visit.

Frequency of tooth brushing, time of tooth brushing and material used for brushing.

Tables 2, 3 and 4 highlights frequency of brushing once/twice/thrice; timing of tooth brushing i.e. before meals/after meals/at morning and night; material used for brushing in male and female distribution and was found that $68.1 \%$ in the $6-9$ years age group and $58.75 \%$ in the $10-13$ years age group brushed twice daily of which $59.6 \%$ and $54.5 \%$ brushed in the morning and at night of which $84.7 \%$ and $84.1 \%$ used paste in the age groups of 6-9 and 10-13 years respectively.

Knowledge about fluoride and use of mouthwashes.

Tables 5 and 6 depicts the children's knowledge about fluorides yes/no and whether they have used mouth washes sometimes/never in male and female distribution in the age groups of 6-9 and 10-13 years age group respectively. Around $1108(100 \%)$ in the age group of 6-9 years age group had no knowledge of fluoride and $1382(99.3 \%)$ in the age group of 10-13 years did not know about fluoride whereas only $10(.7 \%)$ knew about fluoride and around $83.4 \%$ in the age group of 6-9 years and $83.8 \%$ in the age group of 10-13 years did not use mouthwashes.

Frequency of food intake, mouth rinsing habit after meals, frequency of snacking and type of snacks consumed.

Tables 7, 8, 9\& 10 illustrate the frequency of food intake (once/twice/thrice/four times), mouth rinsing habits (yes/no/sometimes), frequency of snacking (once/twice/thrice/four times) by the children in the age group of 6-9 
and 10-13 years respectively. The most frequently used snacks was bread/chips (including biscuits) which was consumed by 539 males and 424 females, pre-cooked noodles was consumed by 494 males and 409 females, whereas sweets (including chocolates) was consumed by 199 males and 218 females and only 44 males and 71 females consumed other type of snacks like beaten rice etc.

\section{Dental visit and reason for visit to dentist.}

Out of 2,500 children assessed, 385 males and 331 females had visited dentist whereas 953 males and 385 females had never been to a dentist. [Table 11]716 children had visited dentist for various reasons like extraction (297 males, 288 females), scaling (19 males, 14 females), restorations (49 males, 15 females) and others like consultation (20 males, 14 females). [Table 12]

\section{How to maintain good oral health.}

Out of 2,500 children assessed, 2,478 (1325 males, 1153 females) responded that to maintain good oral health they would brush twice daily, only 8 ( 5 males, 3 females) children said that they would visit dentist regularly and 14 ( 8 males, 6 females) said that they would reduce the intake of food. [Table 13]

\section{Discussion}

The Silness and L $\varphi$ e plaque index has been widely used to evaluate the level of oral cleanliness in epidemiological studies ${ }^{8}$. Silness and L $\varphi$ e plaque index is easy to use since the criteria are objective, the examinations can be carried out quickly and a high level of reproducibility is possible with minimum training. For these reasons Silness and Lpe plaque index was chosen for this study.

With the trend towards increasing prevalence and severity of dental caries and a concern for the periodontal health of young adults, information concerning the oral hygiene status of young children would assist in the development of oral health policies, strategic plans, monitoring and surveillance systems for oral health. ${ }^{9}$ The overall oral hygiene status of 2,500 children examined was poor which was in concurrence with the findings of Almedia et $\mathrm{al}^{10}$.

In both the age group of 6-9 and 10-13 years, oral hygiene status was evaluated by plaque score. In the present study, plaque score of 3 in 6-9 years is $59.7 \%$ and $40.3 \%$ had plaque score of 4 whereas in 10-13 years age group $62.3 \%$ had plaque score of 3 and $37.7 \%$ had plaque score of 4 shows that 10-13 years had higher percentage of good oral hygiene compared to 6-9 years children. These findings concur with the study by Kumar P et al. ${ }^{11}$ where $80 \%$ of children had good oral hygiene and only $20 \%$ had poor oral hygiene. Rao ${ }^{12}$ found that oral health status of children in the urban school was better than those in rural school and these observations made, coincides with the present study. Thomas et a ${ }^{13}$ found that the plaque scores were high in children before dental health education which was similar to the findings of this study. Al-Banyan etal ${ }^{14}$ found prevalence of gingivitis in $100 \%$ of the children which indicated presence of poor oral hygiene in children. Babu, MS Minor et $\mathrm{a} 1^{15}$ also found that oral hygiene status was poor among rural school children than urban school children.

In 6-9 years age group majority of children i.e. $68.1 \%$ brushed twice daily whereas in 10-13 years age group $58.7 \%$ brushed twice daily showing good oral hygiene practices in children. These findings are in accordance with the findings of Kerstin Westbacke ${ }^{16}$.

The time of tooth brushing as followed by 6-9 years age group mainly consisted of $59.6 \%$ children who brushed in the morning and night before sleeping was compared to $54.5 \%$ of children of $10-13$ years age group and these findings concur with the findings of Kerstin Westbacke ${ }^{16}$ and Kuriakose and Joseph ${ }^{17}$.

In the age group of 6-9 years majority of children i.e. $47.6 \%$ had snacks once daily whereas in 10-13 years age group $36.3 \%$ had snacks once daily and $36.1 \%$ had snacks twice daily. The most frequently used snacks for the 6-9 years old was pre-cooked noodles (42\%) followed by bread/chips (35.2\%), sweets (15.3\%) and home-made snacks (7.8\%) whereas in 10-13 years old $41.2 \%$ consumed bread/chips followed by pre-cooked noodles $(31.5 \%)$, sweets $(17.8 \%)$ and rest had home-made snacks $(9.5 \%)$. These results concur with the study by Kerstin Westbacke ${ }^{16}$.

In the present study only $27.6 \%$ had visited dentist and $72.4 \%$ had not visited any dentist in $6-9$ years age group as compared to $29.5 \%$ who visited dentist and $70.5 \%$ who did not in the $10-13$ years age group. In concurrence with the present study, Addo-Yobo et al., ${ }^{18}$ reported $90 \%$ of children who had not visited the dentist. In contrast to these observations, Weirzbicka et al., ${ }^{19}$ found that in 6 and 12 years children examined, $71 \%$ of children had seen a dentist within one year, $20 \%$ had seen a dentist $1-2$ years ago, $3 \%$ had visited a dentist more than 2 years ago and $8 \%$ had never visited a dentist. 
Knowledge, Attitude and Practice of Oral Hygiene in Children of Eastern Nepal

Table 1. Oral Hygiene Status according to Plaque Score.

\begin{tabular}{|c|c|c|}
\hline \multirow[b]{2}{*}{ Age group } & \multicolumn{2}{|l|}{ Plaque score } \\
\hline & 3 & 4 \\
\hline $6-9$ & $\begin{array}{c}662 \\
59.7 \%\end{array}$ & $\begin{array}{c}446 \\
40.3 \%\end{array}$ \\
\hline $10-13$ & $\begin{array}{c}867 \\
62.3 \%\end{array}$ & $\begin{array}{c}\mathbf{5 2 5} \\
\mathbf{3 7 . 7 \%}\end{array}$ \\
\hline
\end{tabular}

Table 2. Frequency of tooth brushing.

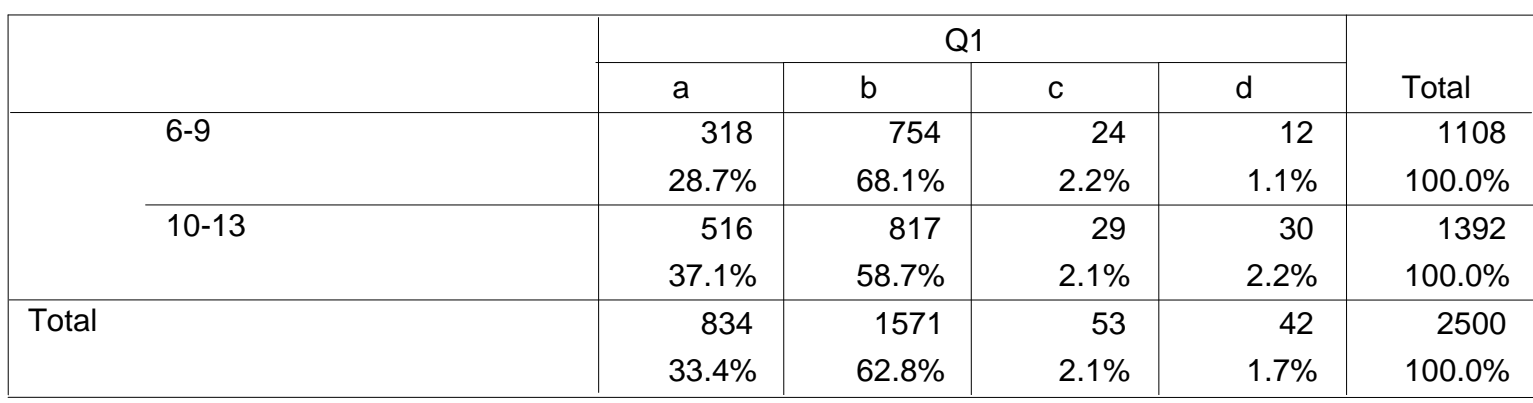

Table 3. Time of tooth brushing.

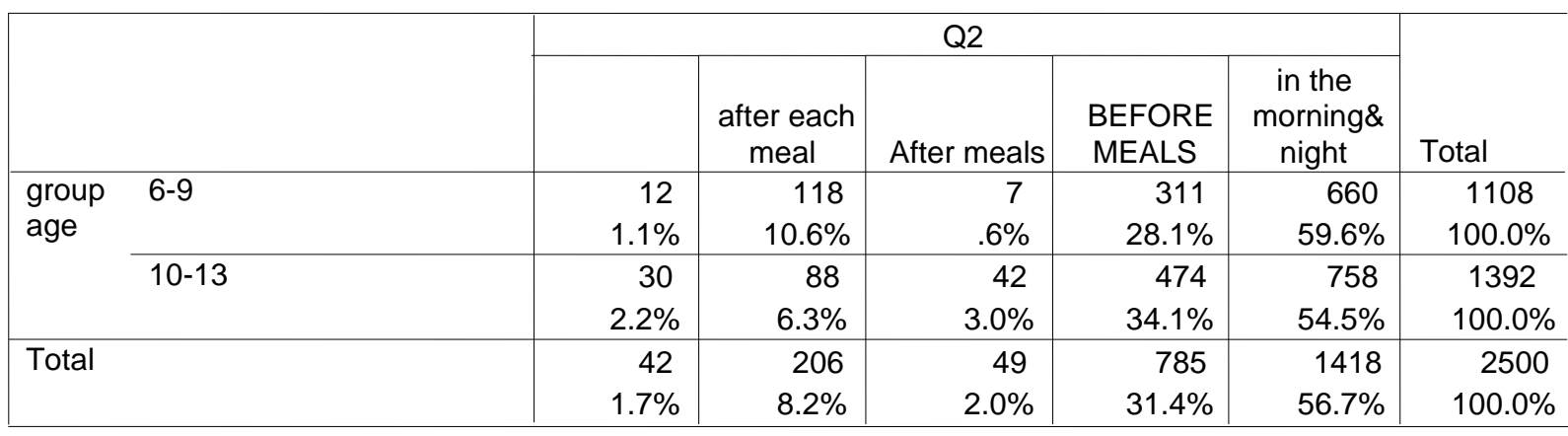

Table 4. Material used for brushing.

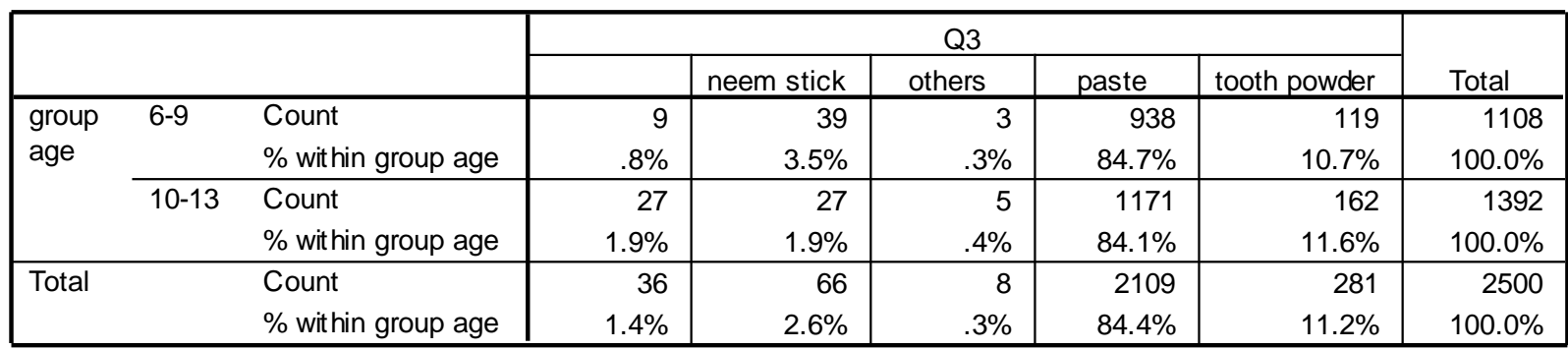

Table 5. Knowledge of fluoride.

\begin{tabular}{|c|c|c|c|c|c|}
\hline & & & \multicolumn{2}{|c|}{ Q5 } & \multirow[b]{2}{*}{ Total } \\
\hline & & & No & Yes & \\
\hline \multirow{4}{*}{$\begin{array}{l}\text { group } \\
\text { age }\end{array}$} & $6-9$ & Count & 1108 & 0 & 1108 \\
\hline & & $\%$ within group age & $100.0 \%$ & $.0 \%$ & $100.0 \%$ \\
\hline & $10-13$ & Count & 1382 & 10 & 1392 \\
\hline & & $\%$ within group age & $99.3 \%$ & $.7 \%$ & $100.0 \%$ \\
\hline \multirow[t]{2}{*}{ Total } & & Count & 2490 & 10 & 2500 \\
\hline & & $\%$ within group age & & $.4 \%$ & $100.0 \%$ \\
\hline
\end{tabular}


Table 6. Use of mouthwashes

\begin{tabular}{|lll|r|r|r|r|}
\hline & & \multicolumn{2}{|c|}{ Q9 } & \\
\cline { 3 - 5 } & & never & \multicolumn{1}{|c|}{ No } & \multicolumn{1}{|c|}{ Yes } & \multicolumn{1}{c|}{ Total } \\
\hline group & $6-9$ & Count & 176 & 924 & 8 & 1108 \\
age & & \% within group age & $15.9 \%$ & $83.4 \%$ & $.7 \%$ & $100.0 \%$ \\
\cline { 2 - 6 } & $10-13$ & Count & 224 & 1166 & 2 & 1392 \\
& & \% within group age & $16.1 \%$ & $83.8 \%$ & $.1 \%$ & $100.0 \%$ \\
\hline Total & & Count & 400 & 2090 & 10 & 2500 \\
& & \% within group age & $16.0 \%$ & $83.6 \%$ & $.4 \%$ & $100.0 \%$ \\
\hline
\end{tabular}

Table 7. Frequency of food intake.

\begin{tabular}{|lll|r|r|r|r|}
\hline & & \multicolumn{2}{|c|}{ Q7 } & \\
\cline { 3 - 6 } & & four times & \multicolumn{1}{c|}{ thrice } & \multicolumn{1}{c|}{ twice } & \multicolumn{1}{c|}{ Total } \\
\hline group & $6-9$ & Count & 110 & 946 & 52 & 1108 \\
age & & $\%$ within group age & $9.9 \%$ & $85.4 \%$ & $4.7 \%$ & $100.0 \%$ \\
\cline { 2 - 6 } & $10-13$ & Count & 178 & 998 & 216 & 1392 \\
& & $\%$ within group age & $12.8 \%$ & $71.7 \%$ & $15.5 \%$ & $100.0 \%$ \\
\hline Total & & 288 & 1944 & 268 & 2500 \\
& & Count & $11.5 \%$ & $77.8 \%$ & $10.7 \%$ & $100.0 \%$ \\
\hline
\end{tabular}

Table 8. Mouth rinsing after meals.

\begin{tabular}{|c|c|c|c|c|c|c|}
\hline & \multicolumn{3}{|c|}{ Q8 } & \multirow[b]{2}{*}{ Total } \\
\hline & & & no & sometimes & yes & \\
\hline \multirow{4}{*}{$\begin{array}{l}\text { group } \\
\text { age }\end{array}$} & $6-9$ & Count & 106 & 63 & 939 & 1108 \\
\hline & & $\%$ within group age & $9.6 \%$ & $5.7 \%$ & $84.7 \%$ & $100.0 \%$ \\
\hline & $10-13$ & Count & 85 & 70 & 1237 & 1392 \\
\hline & & $\%$ within group age & $6.1 \%$ & $5.0 \%$ & $88.9 \%$ & $100.0 \%$ \\
\hline \multirow[t]{2}{*}{ Total } & & Count & 191 & 133 & 2176 & 2500 \\
\hline & & $\%$ within group age & $7.6 \%$ & $5.3 \%$ & $87.0 \%$ & $100.0 \%$ \\
\hline
\end{tabular}

Table 9. Frequency of snacking.

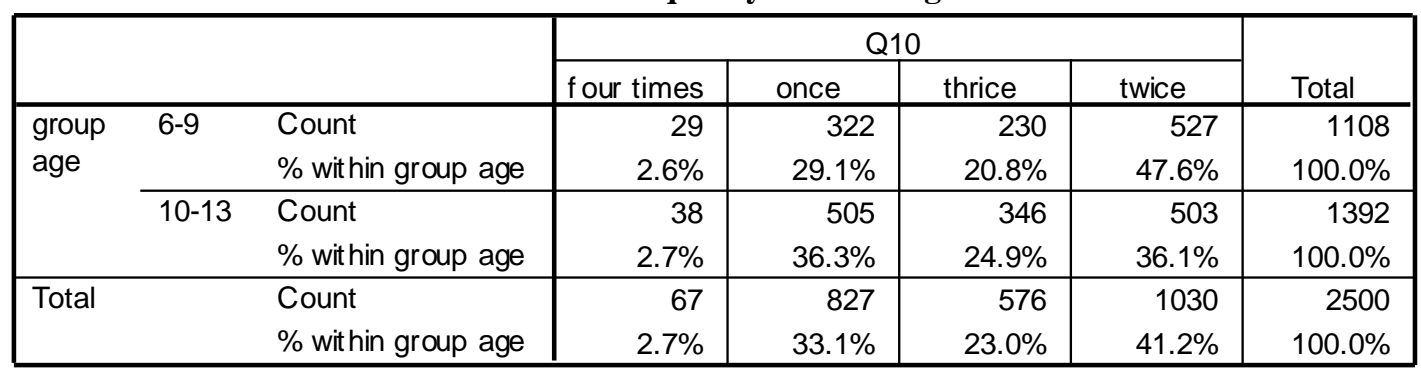

Table 10. Type of snacks consumed.

\begin{tabular}{|c|c|c|c|c|c|c|c|c|}
\hline & \multicolumn{5}{|c|}{ Q11 } & \multirow[b]{2}{*}{ Total } \\
\hline & & & bread/chips & noodles & others & $\begin{array}{l}\text { pre cook } \\
\text { noodles }\end{array}$ & sweets & \\
\hline \multirow{4}{*}{$\begin{array}{l}\text { group } \\
\text { age }\end{array}$} & $6-9$ & Count & 390 & 50 & 34 & 465 & 169 & 1108 \\
\hline & & $\%$ within group age & $35.2 \%$ & $4.5 \%$ & $3.1 \%$ & $42.0 \%$ & $15.3 \%$ & $100.0 \%$ \\
\hline & $10-13$ & Count & 573 & 52 & 81 & 438 & 248 & 1392 \\
\hline & & $\%$ within group age & $41.2 \%$ & $3.7 \%$ & $5.8 \%$ & $31.5 \%$ & $17.8 \%$ & $100.0 \%$ \\
\hline \multirow[t]{2}{*}{ Total } & & Count & 963 & 102 & 115 & 903 & 417 & 2500 \\
\hline & & $\%$ within group age & $38.5 \%$ & $4.1 \%$ & $4.6 \%$ & $36.1 \%$ & $16.7 \%$ & $100.0 \%$ \\
\hline
\end{tabular}


Table 11. Dental visit.

\begin{tabular}{|lll|r|r|r|}
\hline \multirow{2}{*}{} & & \multicolumn{2}{|c|}{ Q12 } & \multirow{2}{*}{ Total } \\
\cline { 3 - 5 } group & $6-9$ & Count & No & \multicolumn{1}{c|}{ Yes } & \multicolumn{1}{c|}{1108} \\
age & & \% within group age & $72.4 \%$ & $27.6 \%$ & $100.0 \%$ \\
\cline { 2 - 4 } & $10-13$ & Count & 982 & 410 & 1392 \\
& & $\%$ within group age & $70.5 \%$ & $29.5 \%$ & $100.0 \%$ \\
\hline Total & & Count & 1784 & 716 & 2500 \\
& & \% within group age & $71.4 \%$ & $28.6 \%$ & $100.0 \%$ \\
\hline
\end{tabular}

Table 12. Reason for visit to dentist.

\begin{tabular}{|c|c|c|c|c|c|c|c|c|}
\hline & \multicolumn{5}{|c|}{ Q13 } & \multirow[b]{2}{*}{ Total } \\
\hline & & & & extraction & filling & others & scaling & \\
\hline \multirow{4}{*}{$\begin{array}{l}\text { group } \\
\text { age }\end{array}$} & $6-9$ & Count & 802 & 248 & 29 & 9 & 20 & 1108 \\
\hline & & $\%$ within group age & $72.4 \%$ & $22.4 \%$ & $2.6 \%$ & $.8 \%$ & $1.8 \%$ & $100.0 \%$ \\
\hline & $10-13$ & Count & 982 & 337 & 35 & 25 & 13 & 1392 \\
\hline & & $\%$ within group age & $70.5 \%$ & $24.2 \%$ & $2.5 \%$ & $1.8 \%$ & $.9 \%$ & $100.0 \%$ \\
\hline \multirow[t]{2}{*}{ Total } & & Count & 1784 & 585 & 64 & 34 & 33 & 2500 \\
\hline & & $\%$ within group age & $71.4 \%$ & $23.4 \%$ & $2.6 \%$ & $1.4 \%$ & $1.3 \%$ & $100.0 \%$ \\
\hline
\end{tabular}

Table 13. What would you do to keep good oral health?

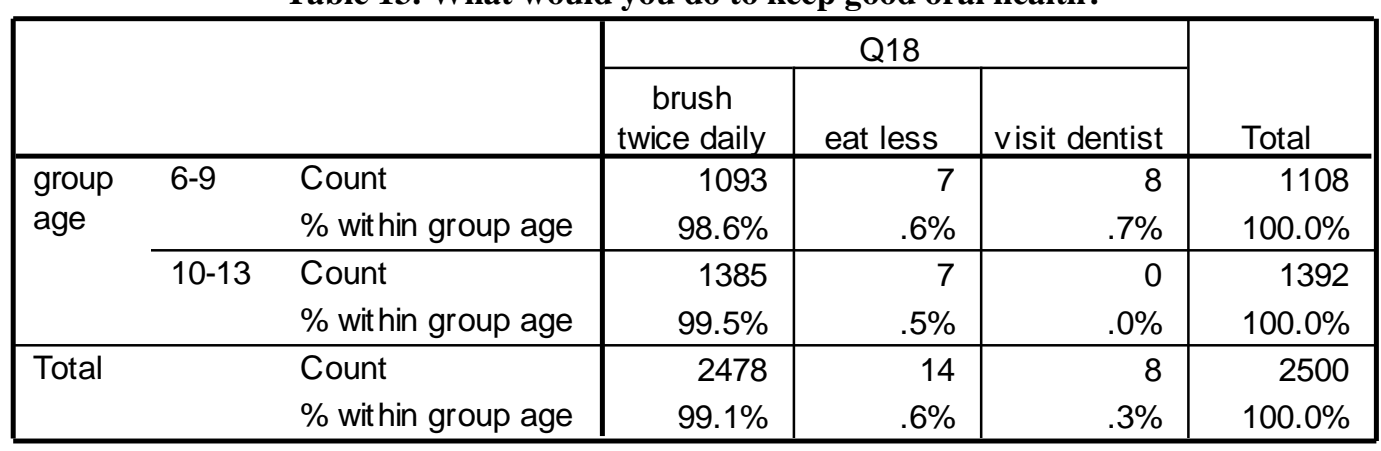

III. Conclusion

Nepal today is faced with a series of problems regarding the oral health of the population. An attempt was made to evaluate the knowledge, attitude and practice of oral hygiene in 2500 children by recording plaque scores and questionnaire. When asked about how to maintain good oral health, majority of children responded that they would brush twice daily to maintain good oral health.The present study concludes that in spite of good oral hygiene practices in children, their overall oral hygiene status was found to be poor indicating a need for community based oral health intervention programs.

\section{References}

[1]. Manuc D, Bulgaru S, Iancu. International perspectives on correlation of CIO behavioral risk factors with dental caries journal of preventive medicine 2006;14(1- 2):46-59.

[2]. Namal N, Vehit HE, Can G. Risk factors for dental caries in Turkish preschool children. Journal of Indian Society of Pedodontics and Preventive Dentistry. 2005;23(3):115-118.

[3]. Rao A, Sequeira S.P, Peter S. Prevalence of dental caries among school children of Moodbidri. J Indian SocPedoPrev Dent1999;17:2:45-48.

[4]. Microbial Physiology. Albert G. Moat, John W. Foster and Michael P. Spector Copyright 2002 by Wiley-Liss, Inc. ISBN: 0-47139483-1

[5]. Hunt RJ. Behavioral and socio-demographic risk factors for caries. In: Bader JD, ed. Risk assessment in dentistry. Chapel Hill: University of North Carolina Dental Ecology 1990; 29-34.

[6]. R. Yee and N. McDonald. Caries experience of 5-6-year old and 12-13-year-old school children in central and western Nepal. International dental Journal 2002; 52: 7-10.

[7]. Central Bureau of Statistics. National Population and Housing Census 2011. Volume 02, NPHC 2011.

[8]. Darby, M. L., \& Walsh, M. M. (2010). Dental hygiene theory and practice third edition. (Third ed.). St. Louis,Missouri: Sanders Elsevier.

[9]. Yee R, David J, Khadka R. Oral cleanliness of 12-13-year-old and 15-year-old school children of Sunsari District, Nepal. J Indian SocPedodPrev Dent 2006;24:146-51.

[10]. C M de Almedia, P E Petersen, SJ Andre and A Toscano. Changing oral health status of 6- and 12-year-old schoolchildren in Portugal. Community Dental Health 2003; 20: 211-216. 
[11]. Mahesh Kumar P, Joseph T, Varma RB, Jayanthi M. Oral health status of 5 years and 12 years school going children in Chennai city - An epidemiological study. J Indian SocPedodPrev Dent 2005;23:17-22

[12]. Rao SP. Dental caries and periodontal diseases among urban, rural and tribal school children. Ind Pediatrics 1993; 30(6): 759-764.

[13]. Thomas S, Tandon S, Nair S. effect of dental health education on the oral health status of a rural child population by involving target groups. J Indian SocPedoPrev Dent2000;18:3:115-125.

[14]. R.A Al-Banyan, E.A Echeverri, S Narendran and H.J Keene. Oral health survey of 5-12-year-old children of National Guard employees in Riyadh, Saudi Arabia. International journal of Pediatric dentistry 2000; 10: 39-45.

[15]. Babu, MS Minor, S. V. S. G. Nirmala, and N. Sivakumar. "Oral Hygiene Status of 7-12 year old School Children in Rural and Urban population of Nellore District." PUBLIC HEALTH 2011.18 SUPPL III.

[16]. Kerstin Westbacke. Hygiene, eating habits and oral health among children in three Nepalese public high schools. MPH 2006;18.

[17]. Kuriakose S, Joseph E. Caries prevalence and its relation to socio-economic status and oral hygiene practices in 600 pre-school children of Kerala-India. J Indian SocPedoPrev Dent1999; 17:3 ; 97-100.

[18]. C. Addo-Yobo, S.A. Williams, M.E.J. Curzon. Dental caries experience in Ghana among 12-year-old urban and rural school children. Caries Res1991; 25:311-314.

[19]. Maria Weirzbicka, Poul Erik Petersen, FranciszekSzatko, ElzbietaDybizbanska and IsufKalo. Changing oral health status and oral behaviour of school children in Poland. Community Dental Health 2002; 19: 243-250. 